\title{
Minute Times Nanomole Per Liter Per Kilogram
}

National Cancer Institute

\section{Source}

National Cancer Institute. Minute Times Nanomole Per Liter Per Kilogram. NCI

Thesaurus. Code C112351.

Minutes times nanomoles per liter, divided by kilograms. 